\title{
Cultural Influences On The Adoption Of Electronic Commerce: Initial Results From Japan And The United States
}

Kathryn M. Kimery, Saint Mary’s University, Halifax, Canada

Samad Amirkhalkhali, Saint Mary’s University, Halifax, Canada

\begin{abstract}
This study adopts a research model based on Diffusion of Innovation Theory, online trust, and national culture. It explores the impact of culture on perceptions of and intentions to adopt electronic commerce.
\end{abstract}

Keywords: diffusion of innovations, e-commerce, culture.

\section{INTRODUCTION}

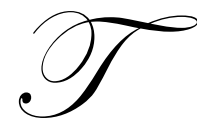

he Internet has developed into a vast global marketplace for the exchange of goods and services. Business-to-consumer electronic commerce (EC) has become the object of considerable research, however, the bulk of this research continues to ignore the possible impacts of national culture on how EC is perceived and adopted around the world.

This study adopts a research model based on Diffusion of Innovation theory, online trust, and national culture to address the basic questions: Does national culture play a role in coloring consumer perceptions of EC innovation characteristics and does culture influence how these perceptions shape consumers' intentions to adopt EC? Comparisons are drawn between consumers in two distinct national cultures, Japan and the United States. This paper presents a brief summary of the research background and research model, propositions, and preliminary results.

\section{BACKGROUND}

While business-to-consumer electronic commerce (EC) is often promoted as a world-wide phenomenon, most published studies have focused on the adoption, diffusion, and impact of EC in Europe and North America. Given the international character of the Internet and its potential as a borderless forum for exchange, it is crucial that EC research have a more global scope. This study furthers the efforts to expand EC research horizons begun by others, including Gibbs, Kraemer, and Dedrick (2003), Van Slyke, Belanger, \& Sridhar (2005), Gefen and Heart (2006), He, Duan, Fu, and Li (2006), and Zhang, Sakaguchi, and Kennedy (2007).

A number of economic, technological, and political factors can influence how consumers in different countries are able to adopt use of the Internet or participate in EC. Some of these factors include reliability of the telecommunications infrastructure, presence of working online payment mechanisms, and convenient and affordable access to personal computers and the Internet (Dutta \& Jain, 2003-2004; Wolcott, Press, Henry, Goodman, \& Foster, 2001). It is becoming increasingly clear, however, that suitability of technological and economic infrastructures do not tell the whole story in explaining Internet and, particularly, EC adoption. Gibbs, et al. (2003) have observed that business-to-consumer EC is an innovation whose adoption is primarily pulled by local consumer markets, and, therefore, local values, attitudes, and preferences will play a key role in encouraging or suppressing its diffusion. Cultural differences between countries and regions have been sited as an important influence on the perceptions consumers form about EC and, further, how these perceptions translate into intentions to adopt EC (e.g., Robey \& 
Rodriguez-Diaz, 1989; Straub, Keil, \& Brenner, 1997; Van Slyke, Lou, \& Belanger, 2001; Van Slyke, et al., 2005; Yap, Das, Burbridge, \& Cort, 2006).

The current research model is depicted graphically in Figure 1. The model suggests that intention to adopt EC is shaped by consumer perceptions of nine key EC attributes: relative advantage (the benefits afforded by online shopping over other shopping venues), compatibility (the consistency of online shopping with an individual's preferred shopping habits), ease of use (the lack of difficulty associated with using the Internet for buying goods and services), visibility (the visibility of the actual technology and processes that comprise EC), result demonstrability (the tangibility of online shopping outcomes), image (the prestige associated with shopping online), Trialability (the ability to experiment with online shopping before committing to its use), voluntariness (the freedom to choose whether or not to shop online), and trustworthiness (the belief that online merchants and systems can be trusted). The first eight factors are taken directly from Diffusion of Innovation (DOI) theory (Rogers, 1983; Moore and Benbasat, 1991). The last factor, Trustworthiness, is drawn from the online trust literature. The model presents these factors as existing within a cultural environment, which exerts influence over how the characteristics are perceived by individuals as well as how the perceived characteristics contribute to the ultimate intention to adopt or reject EC. Each aspect of the model is discussed in the next section.

Figure 1

Research Model

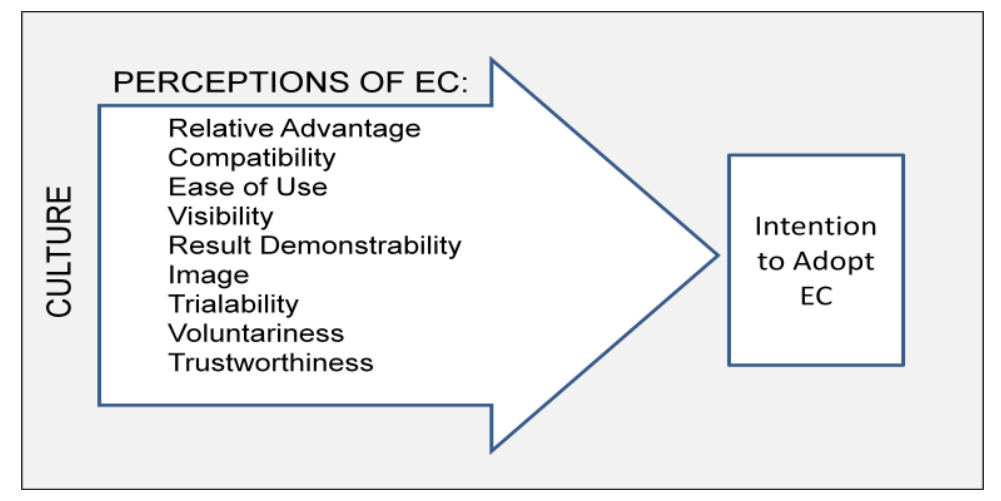

\section{Diffusion of Innovations and Trust}

An innovation is a phenomenon--an idea, process, object, or technology-- that is viewed as something substantially new or different by members of a relevant social group (Zaltman, Duncan, \& Holbek, 1973). Briefly, DOI theory attempts to explain how quickly innovative practices and technologies are adopted by a social group (Rogers, 1983, 1995). Rogers (1995) describes a 'bottom up' diffusion paradigm, in which adoption of an innovation spreads from individual to individual through a multi-stage Innovation Decision Process. During this process, individuals first become aware of an innovation and develop initial information about the innovation. Once the individuals have a basic understanding of the innovation, they decide to either accept or reject adoption. Finally, individuals seek to confirm and reinforce their decisions via actual experience with the innovation or further information gathering.

Rogers (1983) argues that the rate at which individuals move through the multiple stages of the Innovation Decision Process and the likelihood that they will make and confirm positive decisions to adopt an innovation is influenced by perceptions of five key characteristics of an innovation. These innovation characteristics are: relative advantage (superiority of an innovation compared to prior technology or processes), compatibility (consistency of an innovation with the user's experiences, habits, and values), perceived complexity (the relative difficulty to learn and use an innovation), trialability (the ability to try-out the innovation prior to adoption), and observability (the visibility of an innovation's use or results). Moore and Benbasat (1991) considered Rogers' set of 
key characteristics and expanded the list, first, by decomposing the observability factor into two sub-characteristics, perceived result demonstrability (the tangibility of the results of using an innovation) and perceived visibility (the visibility of the innovation itself). Further, they argued that relative advantage actually subsumed a second, independent characteristic, perceived image (the degree to which adoption of the innovation enhances the user's status). They also added perceived voluntariness (the degree to which use of the innovation is unforced) as a final characteristic important for influencing innovation adoption decisions. To make the list of characteristics more internally consistent in terms of the direction of predicted relationships with innovation adoption behaviors, Moore and Benbasat inverted the complexity characteristic and renamed it ease of use. Moore and Benbasat referred to this expanded list as the Perceived Characteristics of Innovating (PCI) factors.

EC is a complex innovation that encompasses not only new hardware and software technologies, but also a new set of interpersonal, organizational, and financial networks and relationships. While the PCI factors were developed to address a broad range of innovations, a substantial body of research in has identified the pivotal role of trust as an enabler of EC adoption (Gefen, 2000; Gefen, Karahanna, \& Straub, 2003; Hoffman, Novak, \& Peralta, 1999; McKnight, Kacmar, \& Choudhury, 2004). Perceived trustworthiness of online merchants is particularly relevant as an enabler of EC adoption, because consumers continue to perceive online shopping as inherently more risky than shopping through traditional face-to-face channels (Metzger, 2006; Grabner-Kraeuter, 2002). The lack of consumer trust in online merchants has been highlighted by numerous authors as a critical barrier to the wide-spread diffusion of EC (e.g., AICPA, 1998; Hoffman et al., 1999, Crowell, 2001). A field study by Hampton-Sosa and Koufaris (2005) reveals that perceived trustworthiness of an online merchant is strongly associated with increased consumer intention to make online purchase, and Gefen, et al. (2003) and Jarvenpaa, Tractinsky, and Vitali (2000) report similar findings.

Based on the strong research support for the role of trust as a facilitator of EC adoption, Van Slyke and colleagues (Van Slyke, Luo, Belanger, \& Sridhar, 2004; Van Slyke, et. al, 2001) incorporated a trust factor in their cross-cultural studies of EC diffusion. Perceived trustworthiness has also been included as a characteristic of EC important for predicting innovation adoption in the research model for this study. Table 1 summarizes the nine factors, representing the eight innovation characteristics drawn from DOI theory and a trust factor, posited to influence EC adoption decisions.

\section{National Culture}

This study draws its cultural framework from the landmark studies of Gerte Hofstede (1980, 1991). Hofstede's cultural indices are not the only approach to categorizing and describing national cultures (i.e., Schwartz, 1994; World Values Survey, 2001), but are, by far, the most widely used and tested in the business research literature. Hofstede identifies four key dimensions of work-related cultural values that he argues can be used to effectively describe and differentiate national cultures. His original four dimensions of national cultureuncertainty avoidance (UA), individualism (IND), masculinity (MAS), and power distance (PD) - were based on extensive surveys across 53 countries. The survey data were summarized to create comparative index scores, ranging from a low score of zero to a maximum score of 100 , for each country on each of the four dimensions. Individuals from national cultures high on the UA dimension are generally uncomfortable with ambiguity in their surroundings and seek to reduce uncertainty and risk in their daily lives. Countries that are low on UA, however, are more comfortable with uncertainty and risk-taking. Individualism reflects the focus of identity in a society. In a high IND country, individual responsibilities and achievements are reinforced as most important. In a low IND country, however, responsibilities and rewards are shared among members of the relevant social group--family, organization, or community. Support and maintenance of the collective is paramount. Masculinity (also referred to as assertiveness in some research (Straub, et al., 1997)) describes the rigidity of sex-based roles in a society and the relative value assigned to stereotypical male and female roles. Countries that are scored higher on MAS have more strict definitions of acceptable male and female behaviors and tend to value competition, aggressiveness, and materialism. Cultures lower on MAS have more fluid sex-roles and place higher value on nurturing and quality-oflife issues. Finally, a country with a high score on PD is characterized by the general acceptance of unequal distribution of power among members of organizations or communities. Conversely, countries scoring lower on PD are more egalitarian, expecting more equal distributions of social, political, and economic power. Table 1 summarizes the four cultural dimensions with brief definitions of each. 
Table 1

Hofstede's Dimensions of Culture

\begin{tabular}{|l|l|}
\hline \multicolumn{1}{|c|}{ Dimension } & \multicolumn{1}{c|}{ Definition } \\
\hline Uncertainty avoidance (UA) & A generally low tolerance for uncertain or risky situations \\
\hline Individualism (IND) & The belief that individuals are primarily responsible for taking care of themselves \\
\hline Masculinity (MAS) & $\begin{array}{l}\text { The prevalence of rigid gender roles and the dominance of stereotypically "male" } \\
\text { characteristics, such as aggressiveness and materialism }\end{array}$ \\
\hline Power distance (PD) & The general acceptance of unequal power distribution in organizations and society \\
\hline
\end{tabular}

\section{RESEARCH PROPOSITIONS}

The research propositions outline three central expectations to be explored in the current study. First, the research model is expected to successfully predict intention to adopt EC in both national cultures examined in this study. Second, perceptions of EC characteristics are expected to differ based on national culture and these differences will be related predictably to specific dimensions of the national culture. Lastly, the strengths of the various factors in the research model are expected to vary predictably based on national culture.

Prior research testing other technology acceptance models has suggested that a model that works well for North American samples may be less effective for samples from other national cultures (i.e., Straub, et al., 1997). Published tests of DOI theory efficacy for predicting technology diffusion in non-North American settings has been quite limited and the results have been mixed. In 2004, Van Slyke, et al., found that while national culture was a significant predictor of intention to adopt EC, a model based, in part, on the PCI factors of DOI theory and a general measure of EC trustworthiness successfully predicted intention to adopt EC among subjects from four national cultures: the U.S., China, Hong Kong, and India. In a related study, Van Slyke, et al. (2005) report that the DOI model, again with the added EC trustworthiness measure, was successful at predicting intention to use EC in both the United States and India. He, et al. (2006) report that, in a Chinese sample, only one factor in the DOI model, compatibility, proved significant in determining organizational adoption of online e-payment systems. Seeking to explain this result, the authors suggest that adoption of e-payment systems was a necessity for the companies involved and, therefore, differing perceptions of e-payment attributes could have little impact on the final decision to adopt or reject the innovation. Given the inconclusive results, we expect that the overall model will effectively predict intentions to adopt EC across national cultures, but do not predict that the model will be equally successful in different cultural settings.

Proposition 1a: The overall research model will successfully predict intention to adopt EC across cultures.

Jarvenpaa, Tractinsky, and Vitale (2000), among others (e.g., Robichaux \& Cooper, 1998; Straub, et al., 1997) have argued persuasively that consumer perceptions of information technologies are influenced by their cultural environments. Van Slyke, et al. (2005) looked at perceptions of EC in samples of consumers from the U.S. and India and found that Indian perceptions of EC were significantly lower on four of six characteristics measured. They suggest that these differences were likely the result of a combination of technical and economic factors (low penetration of personal computers, unreliable and expensive communication networks, more restricted access to credit cards, and less experience with computing, in general, and online shopping, in particular) as well as cultural factors. They explained that the Indian culture ranks relatively low on Hofstede's IND dimension, which may make online shopping less compatible with their general preferences for more personal shopping experiences.

In step with Van Slyke, et al.'s suggestions, we propose that a culture's individualism will be positively related to individuals' perceptions of many EC characteristics. Despite attempts to introduce more social presence into commercial websites, online shopping is still a largely isolated and impersonalized process. Face-to-face interaction between seller and shopper or between one shopper and another is replaced with computer-mediated, asynchronous, text-based communication, with social exchanges only in virtual meeting spaces. It is reasonable to suppose that individuals from low IND cultures may perceive EC as a less hospitable or desirable shopping alternative to traditional, personalized shopping venues. In addition, it has been argued theoretically and demonstrated empirically that members of low IND cultures are less trusting, at least initially, of those outside the 
boundaries of family or community (Yamagishi \& Yamagishi, 1994; Hofstede, 1980). As a result, we expect that individuals in low IND cultures are more likely to report lower levels of perceived trustworthiness than are individuals in high IND cultures. We also expect that subjects in low IND cultures will view the more isolated shopping experience associated with EC as lower in compatibility, visibility, result demonstrability, and image than do subject in high IND cultures.

High levels of UA in a culture may also act to create negative perceptions of EC. Online shopping is generally considered to be inherently more risky than traditional face-to-face shopping due to the virtual nature of the transaction, the inability to physically inspect and take possession of purchased goods, reliance on electronic payment systems, the threat of insecure handling of financial or personal information, and unfamiliar, remotely located participants in the exchange (Miyazaki \& Fernandez, 2001; Sheehan \& Hoy, 2000). Consumers uncomfortable with accepting risk in an online transaction will tend to have more negative perceptions of the relative advantage provided by EC. They are also likely to perceive online shopping as more complex and less easy to use, than do less risk-averse users, as they experience heightened anxiety or find it necessary to devote additional effort toward mitigating the uncertainties encountered in making purchases online (i.e., arranging payments through third-parties or securing COD delivery methods).

Proposition 1b: Perceptions of EC will be generally lower in low IND and high UA countries.

According to Hofstede (1991), high UA countries adopt a “...what is different is dangerous..." mindset (pg. 119). National cultures scored higher on UA tend to be more fearful of the unknown, more hesitant to try new technologies or products, and more risk-averse. Low UA cultures, on the other hand, are typified by more willingness to accept risk and embrace change. More comfort with uncertainty makes it easier for individuals to adapt to new technologies and behaviors, accepting change and uncertainty as normal and desirable. Because of their culturally reinforced disposition to avoid uncertainty and risk, it will be particularly important for consumers in a high UA culture to view EC as familiar.

Proposition 2: Perceived compatibility will be relatively more important for explaining EC adoption in higher UA countries than in lower UA countries.

Further, we predict that factors that are instrumental for decreasing the sense of vulnerability associated with shopping online will be particularly important for predicting intention to adopt EC in a high UA culture. Specifically, we predict that being able to trial, or "test drive", EC will be highly instrumental in high UA countries, where it may act to allay inexperienced online shoppers' fears about using a new technology or adopting new shopping behaviors.

Proposition 3: Perceived trialability will be relatively more important for explaining EC adoption higher UA countries than in lower UA countries.

Lastly, we expect that perception of trustworthiness will have a particularly strong influence on EC adoption decisions in cultures high in UA. Trust has been recognized as, in essence, a coping mechanism to moderate the negative effects of uncertainty and perceived risk in interpersonal transactions (Morgan \& Hunt, 1994; Grabner-Kraeuter, 2002). In cultures where individuals are culturally predisposed to avoid situations perceived as risky or uncertain, trust will play a heightened role in overcoming barriers to adopting new technology.

Proposition 4: Perceived trustworthiness of online merchants will be relatively more important for explaining EC adoption in higher UA countries than in lower UA countries.

Individualism represents the extent to which people in a society prefer to live and work independently rather than as a member of a tight-knit social group. Countries rated high on IND tend to value personal freedom and independence and form looser relationships with family, friends, and their community. High IND countries tend to value uniqueness and seek more individual recognition and status. In contrast to more communal countries, high IND countries are more likely to be motivated to adopt a technology that is considered to be prestigious or that will 
attract positive attention to the user. Communal countries are less likely to adopt new technology as a means of enhancing their personal status or prestige.

Proposition 5: Perceived image will be relatively less important for explaining EC adoption in low IND countries than in high IND countries.

In low IND cultures, people tend to bond closely with extended family, communities, or work groups. Contrasted with high IND countries, individuals in low IND, communal countries feel more desire and obligation to conform to the norms and expectations of their particular group. As a result, individuals in low IND countries are highly motivated to behave in ways that are consistent and compatible with the behaviors of members of their families, communities, or other groups with which they identify. By extension, members of low IND cultures will be more likely to use a technology, like EC, if they believe that it is acceptable to others in their social group. Specifically in terms of EC adoption, then, individuals will be more likely to adopt EC themselves, if they are able to observe others using the technology directly or are able to observe the results of others' use of the technology.

Proposition 6: Perceived visibility and result demonstrability will be relatively more important for explaining EC adoption in lower IND countries than in higher IND countries.

Hofstede describes masculinity (MAS) as representing the relative value ascribed to stereotypical male characteristics in a culture, including such constructs as competition, aggressiveness, achievement, and materialism. High MAS cultures, therefore, are more motivated to adopt new technologies or behaviors that provide them with competitive advantage and enhance their capacity to achieve goals, obtain material goods, and accomplish tasks better or faster. It is reasonable to expect that high MAS countries should be more influenced by relative advantage than are countries rated lower on MAS.

Proposition 7: Relative advantage will be relatively more important for explaining EC adoption in higher MAS countries than in lower MAS countries.

Cultures high in MAS are also characterized as valuing challenge and are, therefore, more likely to approach task complexity as an opportunity to demonstrate competence and mastery rather than as an obstacle to be avoided. This cultural appreciation of achievement and easy acceptance of challenging situations suggests that high MAS countries are less likely to view complexity of a new technology as a barrier to adoption. As a result, we predict that adoption of EC in high MAS countries will be less influenced by perceived EC ease of use than in lower MAS countries.

Proposition 8: Perceived ease of use will be relatively less important for explaining EC adoption in higher MAS countries than in lower MAS countries.

\section{STUDY SETTING: JAPAN AND THE U.S.}

Japan is the world's second-largest consumer economy (Ministry of Economy, Trade and Industry, 2002), and its citizens are renowned for their 'high-tech' lifestyles and enthusiasm for electronic devices (Funk, 2000). Like the U.S., Japan has a relatively high standard of living, as reflected in their per capita gross domestic products ( $\$ 33,800$ compared to $\$ 46,000$ in the U.S.) and high literacy rate (99\% in both countries.). Particularly important for this study, both countries have a nearly identical rate of Internet use (68.7\% in Japan and 68.4\% in the U.S.), and similar personal computer penetration rate $(68.7 \%$ and $71 \%)$ and average annual online spending per Internet user (\$527 and \$692) (CIA, 2008; Grau, 2005; InternetWorld Stats, 2008). The U.S. still has a substantially higher rate of broadband connections, estimated at $89.4 \%$ in the U.S. compared to $61.9 \%$ in Japan, but the gap between the two countries is beginning to close (New Market Research, 2008).

While it is similar to the United States, in terms of economic and technology status, Japan differs considerably from the U.S., and most other western countries, in terms of cultural values and social norms. A review of Table 3 reveals substantial differences between Japan and the United States in at least three of the four cultural dimensions described by Hofstede $(1980,1991)$. Japan scores near the top of the scale on UA, ranking $17^{\text {th }}$, while 
the U.S. scores near the midpoint of the range and ranks near the bottom of the list of 53 countries. The U.S. outscores all other countries on the IND scale, however, with a score of 91, while Japan scores near the midpoint on the scale and ranks $23^{\text {rd }}$ out of all countries in the study. On the MAS scale, Japan ranks first among all countries with a score of 95 , while the U.S. scores a more modest 62 , ranking $15^{\text {th }}$. While Japan scores slightly higher than the U.S. on the PD dimension, both countries are near the mid-point on the 0-to-100 scale. On three of the dimensions, UA, IND, and MAS, there are dramatic, measured differences between the national cultures of Japan and the U.S. On each of these dimensions, Japan and the U.S. can be rated as relatively high or low compared to one another. Japan can be rated as relatively high on the dimensions of UA and MA and relatively low on IND. The U.S., on the other hand, can be rated as relatively low on the dimensions of UA and MA and relatively high on IND. Because of the clear cultural contrast between Japan and the U.S., despite the many similarities between the two countries in terms of economic and technological development, this presents a particularly interesting study setting for exploring our propositions and testing the cross-cultural robustness of the research model.

Table 2

Hofstede's Cultural Dimension Scores

\begin{tabular}{|l|c|c|c|c|c|}
\hline \multicolumn{1}{|c|}{ Dimension } & \multicolumn{2}{|c|}{ Japan } & \multicolumn{2}{c|}{ U.S. } & Difference \\
\hline & $\begin{array}{c}\text { Score* } \\
\text { (rank**) }\end{array}$ & $\begin{array}{c}\text { Relative to } \\
\text { U.S. }\end{array}$ & $\begin{array}{c}\text { Score } \\
\text { (rank) }\end{array}$ & $\begin{array}{c}\text { Relative to } \\
\text { Japan }\end{array}$ & Score (rank) \\
\hline Uncertainty avoidance & $92(17)$ & HIGH & $46(43)$ & LOW & $46(26)$ \\
\hline Individualism & $46(23)$ & LOW & $91(1)$ & HIGH & $45(22)$ \\
\hline Masculinity & $95(1)$ & HIGH & $62(15)$ & LOW & $33(14)$ \\
\hline Power distance & $54(33)$ & --- & $40(38)$ & --- & $14(5)$ \\
\hline
\end{tabular}

* On a scale of $1-100$

** Out of 53 countries studied

\section{METHODOLOGY AND INITIAL RESULTS}

The survey instrument for this study was adapted from that used in previous data collections (Van Slyke, et al., 2005). This original survey was based on the Moore and Benbasat (1991) short-form PCI instrument, with slight rewording to identify EC (specifically, online shopping) as the innovation of interest. All items were measured on 7 point Likert scales, with the exception of demographic questions. Preparation and validation of the instrument was described in an earlier paper (Kimery \& Amirkhalkhali, 2007), but it should be noted that three factors (trialability, visibility, and voluntariness) were dropped from further analysis due to methodological issues. The final instrument included multi-item scales measuring perceptions of the remaining six EC characteristics included in the research model, plus the outcome variable, intention to use EC, as well as 11 demographic questions. A total of 158 usable surveys were collected from students enrolled in courses at a Japanese university. Previously reported results from an American sample of college students, using a similar instrument, are used for comparison with the Japanese sample (Van Slyke, et al., 2005).

Results of regression analysis for the Japanese study sample are presented in Table 3. As asserted in Proposition 1a, the full research model does predict a substantial portion of the variation in the dependent variable, intention to adopt EC, with an adjusted $\mathrm{R}^{2}$ of $.617(f=26.34$, significant at $\alpha=.0001)$. Van Slyke, et al. (2005) also found that the model fit their U.S. sample quite well, reporting an adjusted $\mathbf{R}^{2}$ of $.677(f=25.251$, significant at $\alpha=$ $.001)$.

Proposition $1 \mathrm{~b}$ expresses our expectation that perceptions of EC, in general, will be rated relatively lower by subjects in more communal, higher uncertainty avoiding cultures. As noted before, Japan is a national culture that is both low in IND and high in UA compared to the U.S. (see Table 2) and, therefore, we expect mean ratings on each of the characteristics included in the research model to be significantly lower in Japan than the same ratings reported by Van Slyke, et al. (2005) for the U.S. sample. Table 4 presents the mean ratings for each characteristic from both samples, along with standard deviation and $t$ statistics. These results reveal that mean perceptions of all 
but one of the characteristics are, as expected, significantly lower in Japan than in the United States. There is no significant difference in perceived result demonstrability between the two cultures.

Table 3

Standardized Beta Coefficients for Japan

\begin{tabular}{|l|c|}
\hline Relative Advantage &. $\mathbf{. 7 2}^{*}$ \\
\hline Ease of Use & .006 \\
\hline Compatibility &. $\mathbf{3 8 5}^{*}$ \\
\hline Result Demonstrability & .102 \\
\hline Image & -.046 \\
\hline Trustworthiness &. $\mathbf{1 7}^{*}$ \\
\hline Sex & .027 \\
\hline Prior Online Purchase & .119 \\
\hline Credit Card &. .017 \\
\hline Years Using Computer & .017 \\
\hline Adjusted $\mathrm{R}^{2}$ & .617 \\
\hline
\end{tabular}

* significant at $\alpha=.001$

Table 4

Perceptions of EC Characteristics

\begin{tabular}{|l|c|c|c|c|c|}
\hline & \multicolumn{2}{|c|}{ JAPAN } & \multicolumn{2}{c|}{ U.S. } & t \\
\hline & Mean & Std. dev. & Mean & Std. dev. & \\
\hline Relative Advantage & 4.46 & .99 & 4.85 & 1.19 & $\mathbf{- 3 . 0 1 6}^{*}$ \\
\hline Ease of Use & 4.20 & 1.19 & 5.46 & 0.92 & $\mathbf{- 1 0 . 1 2 4}^{*}$ \\
\hline Compatibility & 2.90 & 1.30 & 4.41 & 1.47 & $\mathbf{- 9 . 1 1 2 *}$ \\
\hline Result Demonstrability & 3.59 & 1.14 & 3.61 & 1.31 & -0.110 \\
\hline Image & 1.99 & 1.38 & 5.43 & .86 & $\mathbf{- 2 9 . 1 3 8} *$ \\
\hline Trust & 2.85 & 1.13 & 3.86 & .89 & $\mathbf{- 8 . 4 5 4} *$ \\
\hline
\end{tabular}

* significant at $\alpha=.001$

Note: Visibility, Trialability, and Voluntariness were dropped from the analysis.

At this stage of analysis, the remaining propositions can be indirectly evaluated by comparing the ranks of significant factors in the Japan vs. U.S. regression results (Table 3). Propositions 2, 4, and 7 state our expectations that perceived compatibility, relative advantage, and trustworthiness will be stronger motivators for EC adoption in high UA and MAS countries, like Japan, than in lower UA and MAS countries, like the United States. While our results do identify compatibility and relative advantage as the most important adoption factors among subjects in Japan, these results are matched by those reported for U.S. subjects (Van Slyke, et al., 2005). Perception of compatibility and relative advantage appear to be consistently important for determining EC adoption, despite the cultural differences, in Japan and the United States, failing to support Propositions 2 and 7.

Differences between the two groups do not emerge until we consider the next factor in order of importance. In Japan, the third most important factor is perceived trustworthiness, while in the U.S., it is ease of use. In Japan, perceived trustworthiness is a highly significant $(p<.001)$ factor, reflecting the fact that, among Japanese subjects, their ability to trust online merchants is instrumental in determining whether or not EC will be adopted or rejected. Consumers in the U.S. are less inclined to take trustworthiness of merchants into serious consideration as they decide to participate in online shopping. These findings support our expectation expressed in Proposition 4.

Proposition 8 states that we expect ease of use to be less important for consumers in highly masculine cultures compared to consumers in less masculine cultures. This proposition is supported by our results. In the U.S. sample, the third, and final, factor to have a significant impact on EC adoption is ease of use, while this characteristic is an insignificant factor in the Japan sample. This implies that U.S. consumers are more likely to 
participate in EC, if they believe that the technologies and processes involved are simple and relatively easy to learn and use. As predicted, however, we can argue that Japanese consumers are much less concerned about the difficulty of adopting EC.

Propositions 5 and 6 are not supported in this initial analysis, because image and result demonstrability are insignificant predictors of intention to adopt EC in both the Japan and U.S. samples. Finally, Proposition 3, as well as parts of Proposition 6, could not be evaluated, because the relevant factors were dropped prior to analysis for methodological reasons.

\section{CONCLUSIONS}

The main objective of this research project is to further our understanding of cultural influences on EC diffusion. We hope to clarify how cultural differences affect consumer perceptions of electronic commerce and how these perceptions are melded into decisions to participate in the EC marketplace. A research model based on Diffusion of Innovation theory, online trust, and national culture has been laid as a foundation. The very preliminary results provide tentative support for at least some of the propositions presented in this paper. The initial results highlight some interesting possibilities concerning the influence of culture on willingness to adopt innovations. Countries with cultures that are high in uncertainty avoidance and low in individualism do appear to have significantly lower perceptions of most factors identified as critical for EC adoption. Subjects from Japan provide significantly more negative ratings than subjects from the U.S. for EC relative advantage, compatibility, ease of use, image, and trustworthiness. Despite the less favorable perceptions of EC characteristics, the full research model does prove to be a good predictor of intention to adopt EC in Japan. Based on a well-established framework of cultural dimensions, we are able to successfully anticipate some interesting differences in how perceptions of EC are transformed into decisions to adopt or reject EC across two different cultures. The initial results suggest that, compared to other cultural groups, the decision to adopt an innovation in cultures, like Japan, that are high in uncertainty avoidance and masculinity are more strongly influenced by perceptions of trustworthiness of the participants responsible for the innovation-related processes and are less influenced by the simplicity and ease of using the innovation.

Once completed, this study promises to provide unique insights into the process of global innovation diffusion and, more specifically, to provide guidance for researchers, as they develop new streams of EC research, and to practitioners, as they plan strategies to enhance and enrich the Internet as a borderless, accessible world marketplace.

\section{AUTHOR INFORMATION}

Dr. Kathryn Kimery is Associate Professor of Computing and Information Systems at Saint Mary's University in Halifax, NS, Canada. Her research focuses on electronic commerce and social aspects of computing, and has been published in journals, including Journal of Business Research, Journal of Information Technology Theory and Application, and Journal of Electronic Commerce in Organizations, as well as in numerous refereed proceedings.

Dr. Samad Amirkhalkhali is Associate Professor of Management Science at Saint Mary's University. His publications include papers in journals, such as Empirical Economics, Southern Economic Journal, Canadian Journal of Economics, Economic Modeling, The Statistician (published by the Royal Statistical Society), and Journal of Statistical Computation and Simulation, and many refereed proceedings.

\section{REFERENCES}

1. AICPA - American Institute of Certified Public Accountants (1998) Electronic commerce assurance: Attitudes toward CPA WebTrust. Retrieved November 13, 2002, from http://www.aicpa.org/webtrust/yankel.htm.

2. Central Intelligence Agency (2008) The World Factbook. Retrieved May 20, 2008, from http://www.cia.gov/library/publications/the-world-factbook/ .

3. Crowell, W. (2001). Trust, the e-commerce difference. Credit Card Manager, 14(5):80. 
4. Dutta, S., \& Jain, A. (2003-2004) The Network Readiness Index 2003-2004: Overview and analysis framework (Ch. 1). INSEAD. Retrieved May 1, 2006, from http://www.weforum.org/pdf/Gcr/GITR 2003 2004/ Framework_Chapter.pdf

5. Funk, J. (2000), The Internet Market: Lessons from Japan's I-mode System, Kobe University, Japan.

6. Gefen, D. (2000) E-commerce: The role of familiarity and trust. Omega, 28(6): 725.

7. Gefen, D., \& Heart, T. (2006) On the need to include national culture as a central issue in e-commerce trust beliefs. Journal of Global Information Management, 14(4): 1-30.

8. Gefen, D., Karahanna, E., \& Straub, D. W. (2003). Trust and tam in online shopping: An integrated model. MIS Quarterly, 27(1): 51-90.

9. Gibbs, J., Kraemer, K., Dedrick, J. (2003). Environment and policy factors shaping global e-commerce diffusion: A cross-country comparison. Information Society, 19(1), 5-18.

10. Grabner-Kraeuter, S. (2002) The role of consumers' trust in online-shopping. Journal of Business Ethics, 39(1/2), 43-50.

11. Grau, J. (2005) Looking to Asia for Sales. I-Media Connection. Retrieved May 20, 2008, from http://www.imediaconnection.com/content/6090.asp .

12. Hampton-Sosa, W., \& Koufaris, M. (2005). The effect of web site perceptions on initial trust in the owner company. International Journal of Electronic Commerce, 10(1), 55-81.

13. He, Q., Duan, Y., Fu, Z., \& Li, D. (2006) An innovation adoption study of online e-payment in Chinese companies. Journal of Electronic Commerce in Organizations, 4(1): 48-69.

14. Hoffman, D., Novak, T., Peralta, M. (1999). Building consumer trust online, Communications of the ACM, 42(4): 80-85.

15. Hofstede, G. (1980). Culture's Consequences. Beverly Hills, CA: Sage Publications.

16. Hofstede, G. (1991). Cultures and Organizations: Software of the Mind. New York: McGraw-Hill.

17. Internet World Stats (2008) Internet World Stats Usage and Population Statistics. Retrieved May 20, 2008, from http://www.internetworldstats.com/ .

18. Jarvenpaa, S. L., Tractinsky, N., \& Vitale, M. (2000). Consumer trust in an Internet Store. Information Technology and Management Journal, 1: 45-71.

19. Kimery, K., \& Amirkhalkhali, S. (2007) Cultural differences in diffusion of innovation: A comparison of Japan dn the United States. 2007 EABR (Business) \& ETLC (Teaching) Conference Proceedings, 1-11.

20. McKnight, D. H., Kacmar, C. J., \& Choudhury, V. (2004). Shifting factors and the ineffectiveness of third party assurance seals: A two-stage model of initial trust in a web business. Electronic Markets, 14(3), 252266.

21. Metzger, M., (2006) Effects of site, vendor, and consumer characteristics on web site trust and disclosure, Communication Research, 33(34): 155-179

22. Ministry of Economy, Trade and Industry, Electronic Commerce Promotion Council of Japan, and NTT DATA Institute of Management Consulting, Inc. (2002), The Market Research on Electronic Commerce 2001. Retrieved Feb 4, 2007, from http://www.ecom.jp/ecom_e/press/press20020219_1.htm .

23. Miyazaki, A., \& Fernandez, A. (2001) Consumer perceptions of privacy and security risks for online shopping. Journal of Consumer Affairs, 36, 28-49.

24. Moore, G.C., \& Benbasat, I. (1991). Development of an instrument to measure the perceptions of adopting an information technology innovation. Information Systems Research, 2(3), 192-222.

25. Morgan, R., \& Hunt, S., (1994) The commitment-trust theory of relationship marketing. Journal of Marketing, 58(3): 20.

26. New Media Review (2008) Markets by Country. Retrieved May 20, 2008, from http://www.etcnewmedia.com/review/default.asp?SectionID=11\&CountryID=93 and http://www.etcnewmedai.com/review/default.asp?SectionID=11\&CountryID=65

27. Robey, D., \& Rodriguez-Diaz, A. (1989) The organizational and cultural context of systems implementation: Case experience from Latin America. Information and Management, 17(4): 38-53.

28. Robichaux, B., \& Cooper, R. (1998) GSS participation: A cultural examination. Information and Management, 33: 287-300.

29. Rogers, E.M. (1983). Diffusion of Innovations. ( $3^{\text {rd }}$ ed.), New York: The Free Press.

30. Rogers, E.M. (1995) Diffusion of Innovations. $\left(4^{\text {th }}\right.$ ed.), New York: The Free Press. 
31. Schwartz, S. (1994) Beyond individualism/collectivism: New cultural dimensions of values, in Individualism and Collectivism: Theory, Method, and Applications, U. Kim et al., Eds. Thousand Oaks, CA: Sage Publications, pg. 85-119.

32. Sheehan, K., \& Hoy, M. (2000). Dimensions of privacy concern among online consumers. Journal of Public Policy \& Marketing, 19: 62-73

33. Straub, D., Keil, M., \& Brenner, W. (1997) Testing the technology acceptance model across cultures: A three country study. Information \& Management, 33:1-11.

34. Van Slyke, C., Lou, H., \& Belanger, F. (2001) Cultural differences in perceptions of electronic commerce: A comparison of three countries. Proceedings of the Decision Science Institute.

35. Van Slyke, C., Lou, H., Belanger, F., \& Sridhar, V. (2004) The influence of culture on consumer-oriented electronic commerce adoption. Proceedings of the Southern Association for Information Systems.

36. Van Slyke, C., Belanger, F., \& Sridhar, V. (2005) A comparison of American and Indian consumers' perceptions of electronic commerce. Information Resources Management Journal, 18(2):24-40.

37. Wolcott, P., Press, L., McHenry, W., Goodman, S., \& Foster, W. (2001) A framework for assessing the global diffusion of the Internet. Journal of the Association for Information Systems, 2(6).

38. World Values Survey (2001) World Values Survey. Retrieved May 2007 from http://www.worldvaluessurvey.org/

39. Yamagishi, T., \& Yamagishi, M. (1994) Trust and commitment in the United States and Japan. Motivation and Emotion, 18: 129-166.

40. Yap, A., Das, J., Burbridge, J., \& Cort, K. (2006) A composite-model for e-commerce diffusion: Integrating cultural and socio-economic dimensions to the dynamics of diffusion. Journal of Global Information Management, 14(3): 17-38.

41. Zaltman, G., Duncan, R., \& Holbek, J. (1973) Innovations and Organizations. New York: Wiley.

42. Zhang, X., Sakaguchi, T., \& Kennedy, M. (2007). A cross-cultural analysis of privacy notices of the Global 2000. Journal of Information Privacy \& Security, 3(2): 18-36. 
International Business \& Economics Research Journal - June 2009

Volume 8, Number 6

NOTES 